\title{
Accessibility patterns: Bavaria Case Study ${ }^{1}$
}

\author{
Klaus Spiekermann \\ Spiekermann \& Wegener, Urban and Regional Research (S\&W) \\ Lindemannstrasse 10 \\ D-44137 Dortmund, Germany \\ ks@spiekermann-wegener.de
}

\begin{abstract}
This case study covers the Federal State of Bavaria located in the southern part of Germany. Bavaria includes very different types of regions, ranging from the high-density monocentric agglomeration of Munich and medium-sized polycentric agglomerations, to semi-urban surroundings of the agglomerations and to rural structures with small and medium-sized cities which include also mountainous areas, in particular the Alps. The spatial differentiation of Bavaria from the point of view of accessibility very much depends on the type of destination opportunity under consideration. Accessibility of opportunities of the basic needs seems rather balanced. However, accessibility of higher level services such as hospitals is distributed across the region less evenly. For such facilities, there are only some hundred locations in Bavaria, and those are primarily located in cities that have a higher position in the city hierarchy. Between those central places, there are often extensive areas with clearly lower accessibility. This is especially pronounced when accessibility by public transport is concerned.
\end{abstract}

Keywords: accessibility, transport infrastructure, Accessibility pattern, GIS, Bavaria.

\section{Case study introduction}

This case study covers the Federal State of Bavaria located in the southern part of Germany. With surface area of about $70,500 \mathrm{~km}^{2}$, Bavaria is the largest NUTS 1 region in Germany. With a total population of 12.5 million people, it is the second largest state of Germany, only the high-density state of North Rhine-Westphalia has more inhabitants. Bavaria consists of seven NUTS 2 regions, 96 NUTS 3 regions and 2,056 municipalities.

\section{Spatial structure}

In Bavaria there are very different types of regions ranging from the high-density monocentric agglomeration of Munich and medium-sized polycentric agglomerations (Nuremberg-Fürth), to

1 This paper has been developed under the applied research project TRansport ACCessibility at regional/local scale and patterns in Europe led by Spiekermann \& Wegener Urban and Regional Research (S\&W) Germany. It has been financed by the ESPON 2013 Programme and its financial support is gratefully acknowledged. Texts, maps and conclusions stemming from research projects under the ESPON programme presented in this paper do not necessarily reflect the opinions of the ESPON Monitoring Committee. C ESPON, 2013. 
semi-urban surroundings of the agglomerations and to rural structures with small and medium-sized cities which include also mountainous areas, in particular the Alps (Figure 1).

Munich is the capital of Bavaria and the largest city with a population of more than 1.3 million in the municipality and about 2.5 million in the agglomeration. Nuremberg with about 0.5 million inhabitants and Augsburg with 250,000 inhabitants follow, but are clearly smaller in size. There are only five more cities with a population of slightly more than 100,000. Two-thirds of the population live in small and medium-sized cities and rural areas of less than 20,000 inhabitants per municipality.

Consequently, the spatial structure of Bavaria case study region is very heterogeneous. The agglomerations of Munich and Nuremberg are major centres in a more urbanised arc starting in the north-west of Bavaria and running through the two agglomerations towards the south. From this arc towards the outer boundaries of Bavaria, the regions are getting less dense, more rural and peripheral. In terms of area size, rural areas dominate the macro-region of Bavaria.

Heterogeneity is also reflected in the different ESPON typologies. In the urban-rural typology, almost 10 percent of the 96 NUTS 3 regions are classified as urban, about 45 percent as intermediate and another 45 percent as rural. Almost one-third of the regions are classified as metropolitan, of which 20 percent of all regions belong to big metropolitan areas. More than a quarter of the regions are classified as border regions. Also a quarter of the regions are classified as mountainous, most of them under urban influence.

\section{Socio-economic situation}

Bavaria is considered one of the most successful regions of Germany during the economic transformation in the past decades. Since World War II, Bavaria has developed from an agrarian economy to a high-tech economy with a concentration of modern industries in and around the larger cities. GDP growth rates of Bavaria have been usually higher than for Germany as a whole. Compared to the average GDP (in PPS) of EU-27, the index for Bavaria is about 135. Unemployment rates in Bavaria are the lowest in Germany and currently little above 3.5 percent. Consequently, Bavaria has experienced steady population increases during the last decades based on a positive migration balance with all other German Länder and with other countries.

\section{Transport aspects}

As most German regions, Bavaria is very well served by the national motorway network in which major investments have been made during the last decades. Within Bavaria, a mesh-like motorway structure with only very few remaining gaps is connecting the different parts of the state. Several motorways lead to other parts of Germany as well as to international destinations such as Prague, Vienna or via the Brenner motorway to northern Italy. The motorway network is complemented by a dense system of national and state roads connecting also small and medium-sized towns.

The public transport network is based on a relatively dense rail network composed of high-speed train services and regional and local train services. However, as in other parts of Germany, the rail services in Bavaria have been reduced in rural areas, whereas agglomerations have partly seen investments in new infrastructure and services. The rail network is complemented by tram and underground networks in the agglomerations and by a dense bus network serving small and medium-sized cities and rural areas. However, the frequency of many bus lines serving rural areas is rather low. Here the bus network primarily consists of bus services that drive pupils to school and back home, i.e. running only once or twice per day in each direction and not on weekends. 


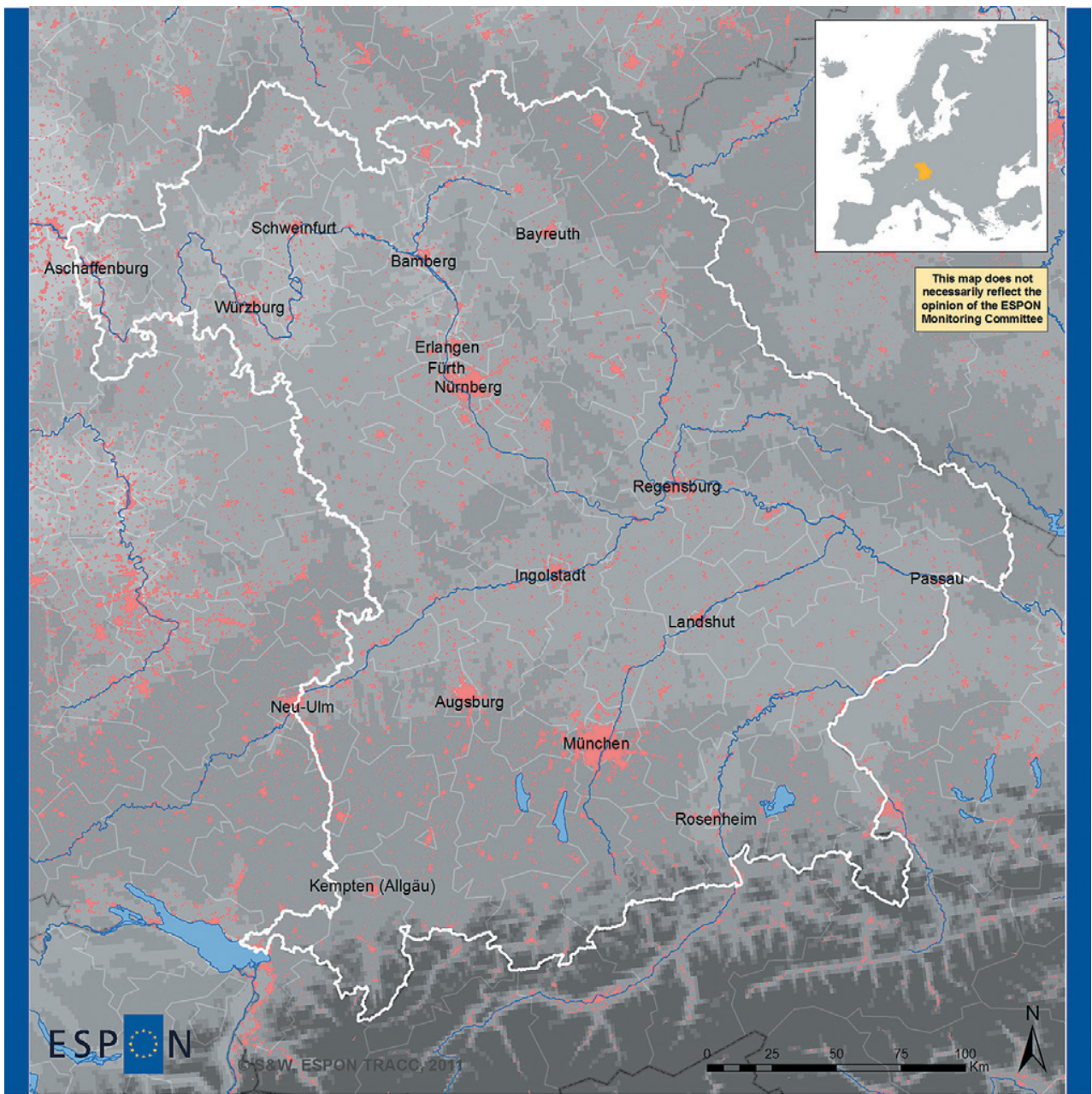

EUROPEAN UNION

Part-financed by the European Regional Development Fund INVESTING IN YOUR FUTURE

Source: S\&W Bavaria Accessibility Model, 2012 Origin of local data: StMWIVT Origin of map data: ESPON Database 2013 (๑) EuroGeographics Association for administrative boundaries

\section{Bavaria Case Study}

Topography

\section{Case study region \\ - National border \\ Settlement area \\ River / lake}

Figure 1. Bavaria case study region.

Air and waterway connections of Bavaria are less important for the analysis of regional and local accessibility patterns. The Munich airport located more than $30 \mathrm{~km}$ northeast of the city centre is one of the major German airport hubs serving many national, international and intercontinental destinations. Though located far away from the sea, Bavaria is well integrated into the European 
inland waterway system. Via the navigable rivers of the Main flowing into the Rhine and the Danube and the connecting Main-Danube-Canal, Bavaria has waterway links with ports located at the North Sea as well as at the Black Sea and the eastern parts of the Mediterranean Sea.

\section{Accessibility patterns}

This section presents selected results of the accessibility analysis for Bavaria (Spiekermann, 2013). As for the other six case study regions of the ESPON TRACC project, six different indicators were calculated for accessibility by car and accessibility by public transport. This section provides the most important information of the selected results, applying the same selection as in the case of other chapters of the presented volume (cf. Biosca et al., 2013). The accessibility analysis for Bavaria provides deeper understanding of regional and local accessibility patterns for a variety of regional types including large agglomerations, urban-rural settings, rural areas and mountain areas.

The accessibility model was set up for the entire macro region of Bavaria in a previous study (Schürmann \& Spiekermann 2010). The main characteristic of the model is its spatial detail. The accessibility model includes a raster cell representation of Bavaria. The region is subdivided into some 7 million raster cells, each of 1 ha in size. The population is allocated to the raster cells by appropriate disaggregation techniques. This means that starting from municipality population figures, each person has got an "address" in form of a raster cell in a microsimulation exercise. The disaggregation is controlled by information on land use type and building footprint. The result of the disaggregation is a raster representation of the population in which for each raster cell the number of inhabitants and their age are known. This synthetic population at raster cells constitutes the origin of the accessibility modelling.

The network database matches the detailed spatial representation of the region. The modes addressed are road and public transport. The road network includes all roads of the region with all residential streets. The public transport network is derived from digital public transport timetable information. It covers all public transport services in Bavaria including all rail, underground, tram and bus services. To calculate travel time between the origins, i.e. the population at raster cell level, a minimum path algorithm is applied. The travel time is an approximation of door-to-door travel time. Car travel time includes the time necessary to get the car started, the time across the network and the time necessary to park the car. Public transport travel time includes walking time to a public transport stop, waiting time, travel time on public transport including any waiting and transfer time, and walking time from the last stop to the final destination.

The accessibility model for the Bavarian macro-region was used to calculate the variety of accessibility indicators. Results can be presented for the raster level and can be aggregated to municipalities. Aggregation from raster cells to municipalities is population-weighted. In this paper, only results at the municipality level are presented. The remaining part of the paper presents four selected accessibility indicators of which each is presented for one mode only. The full range of accessibility indicators for both modes is documented in the Bavaria case study report of the TRACC project (Spiekermann 2013).

\section{Daily accessibility of jobs by car}

The consideration of access to jobs is an important factor when making decisions concerning residential locations. The indicator "daily accessibility of jobs" looks at the availability of jobs within 
travel time from home of 60 minutes. This one hour travel time can be considered a value which most people are willing to accept as a maximum for one-way daily commuting time.

On average, each Bavarian resident has almost 300,000 jobs in reach from his/her residential location within one hour travel time by car. However, the spatial differences are vast (Figure 2). The agglomerations of Munich and Nuremberg offer the highest job availability. In Munich, each resident has 1 million jobs in reach in the maximum commuting time of one hour. As most of the jobs in those agglomerations are located in the core city, daily accessibility of jobs gradually decreases towards the outer parts of the agglomeration. Residents in urban agglomerations have average daily accessibility of jobs of about 800,000 . The situation is very distinct in the countryside. From locations in rural regions, only 100,000 jobs are accessible, while from peripheral rural regions only about 30,000 jobs. The regions in between rural areas and the two big agglomerations offer a fairly good job accessibility of almost 200,000 jobs on average. Those intermediate regions often consist of smaller agglomerations such as Augsburg, Ingolstadt or Würzburg.

The situation in terms of accessibility of jobs for people not having access to a car is much worse. On average, a Bavarian resident can only access about 70,000 jobs within 60 minutes' travel time. The number is somewhat higher for residents of urban regions ( 250,000 jobs), but job access by public transport from rural sites is extremely low (about 10,000 jobs on average).

\section{Regional accessibility potential by car}

The indicator "potential accessibility by car" uses the population as destination activity. The indicator is calculated for a place as the sum of the population in all other places which are weighted by the respective car travel time to those place by using a negative exponential function. In this way, potential accessibility can be interpreted as the market potential of an area or seen differently as the contact potential of the population.

The spatial pattern of the accessibility potential by car is shown in Figure 3. The indicator is presented for the municipalities as index values by which the Bavarian average is set to 100 . Not surprisingly, the highest accessibility potential can be found in the Munich agglomeration. In the city of Munich, the indicator value is more than twice the average. Due to the dense road network, the area of above-average accessibility around Munich is relatively wide. The radial motorways push the areas of higher potential accessibility to the outside and form corridors with high market potential. The Nuremberg region forms the second accessibility peak in Bavaria, however the maximum values are much lower due to a smaller population living in that agglomeration. From the two agglomerations, accessibility potential decreases when moving to more remote areas. Yet, due to the more smoothing character of the indicator's definition, the disparities are less pronounced and the average of rural areas is about 70 percent of the Bavarian average.

Again, the situation for public transport users is much worse. The average accessibility potential by public transport is only about 30 percent of the car average. Even in urban agglomerations, the public transport average goes only up to 70 percent. In rural areas it is as low as 15 percent of the average Bavarian accessibility potential by car. However, the spatial pattern is rather similar with peaks in Munich and Nuremberg and rail services extending the area of higher accessibility to the surrounding cities. This is in particular true for Augsburg which benefits from high-speed train connections to Munich in terms of potential accessibility. 


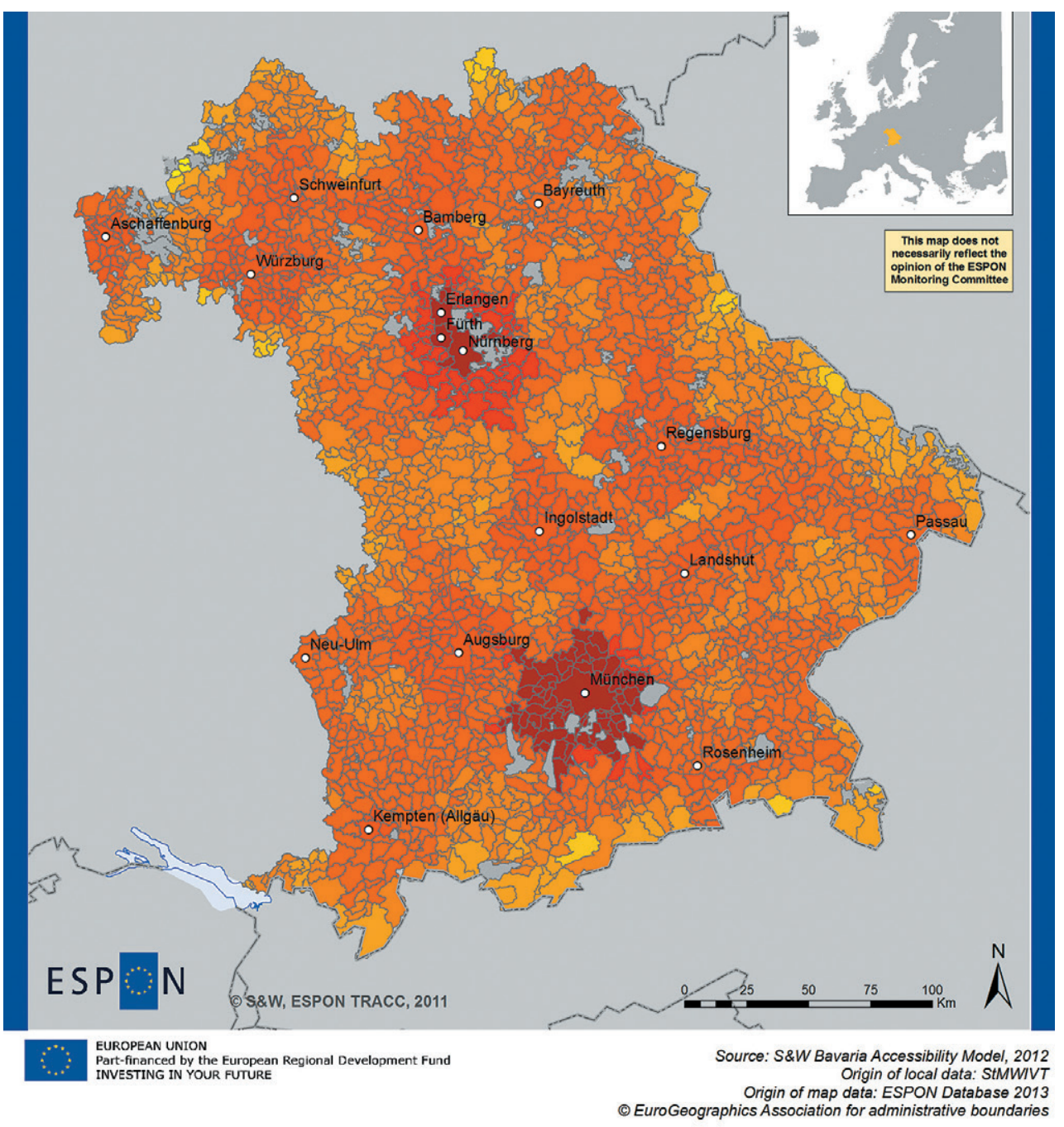

\section{Bavaria Case Study Jobs accessible by car within 60 minutes (in 1.000 jobs)}
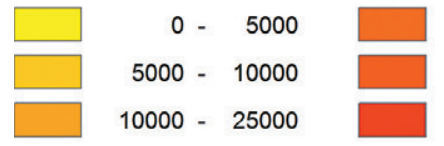

$50000-100000$

$100000-250000$

$250000-500000$

Figure 2. Jobs accessible within 60 minutes by car. 


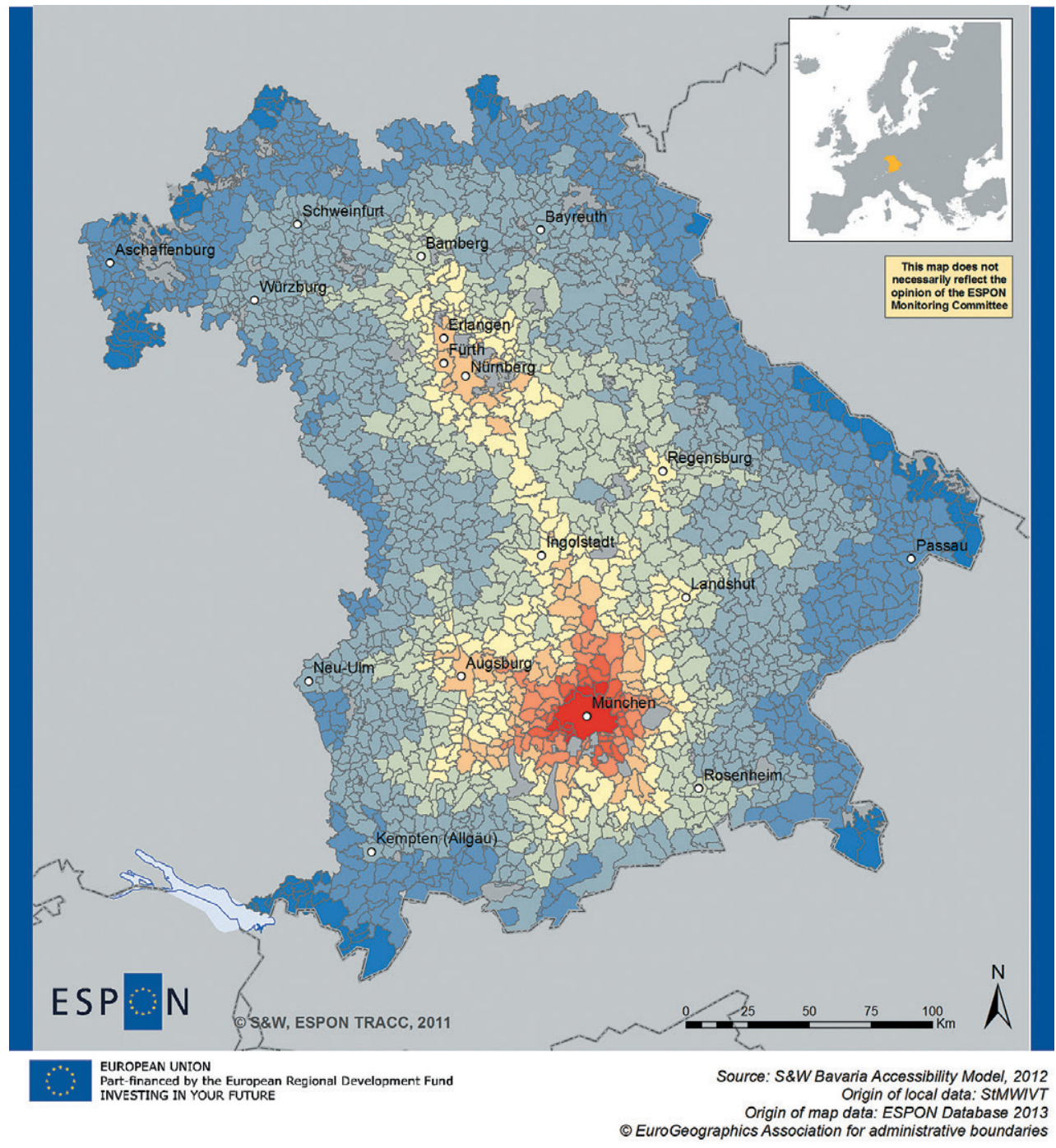

\section{Bavaria Case Study Potential accessibility to population by car (Index: car average $\mathbf{= 1 0 0}$ )}

\begin{tabular}{rl}
$0-25$ & $\square$ \\
\hline & $125-150$ \\
$25-50$ & $\square$ \\
$50-75$ & $150-175$ \\
$50-75-200$ \\
$75-100$ & $200<$ \\
$100-125$ & Unincorporated area
\end{tabular}

Figure 3. Potential accessibility to population by car. 


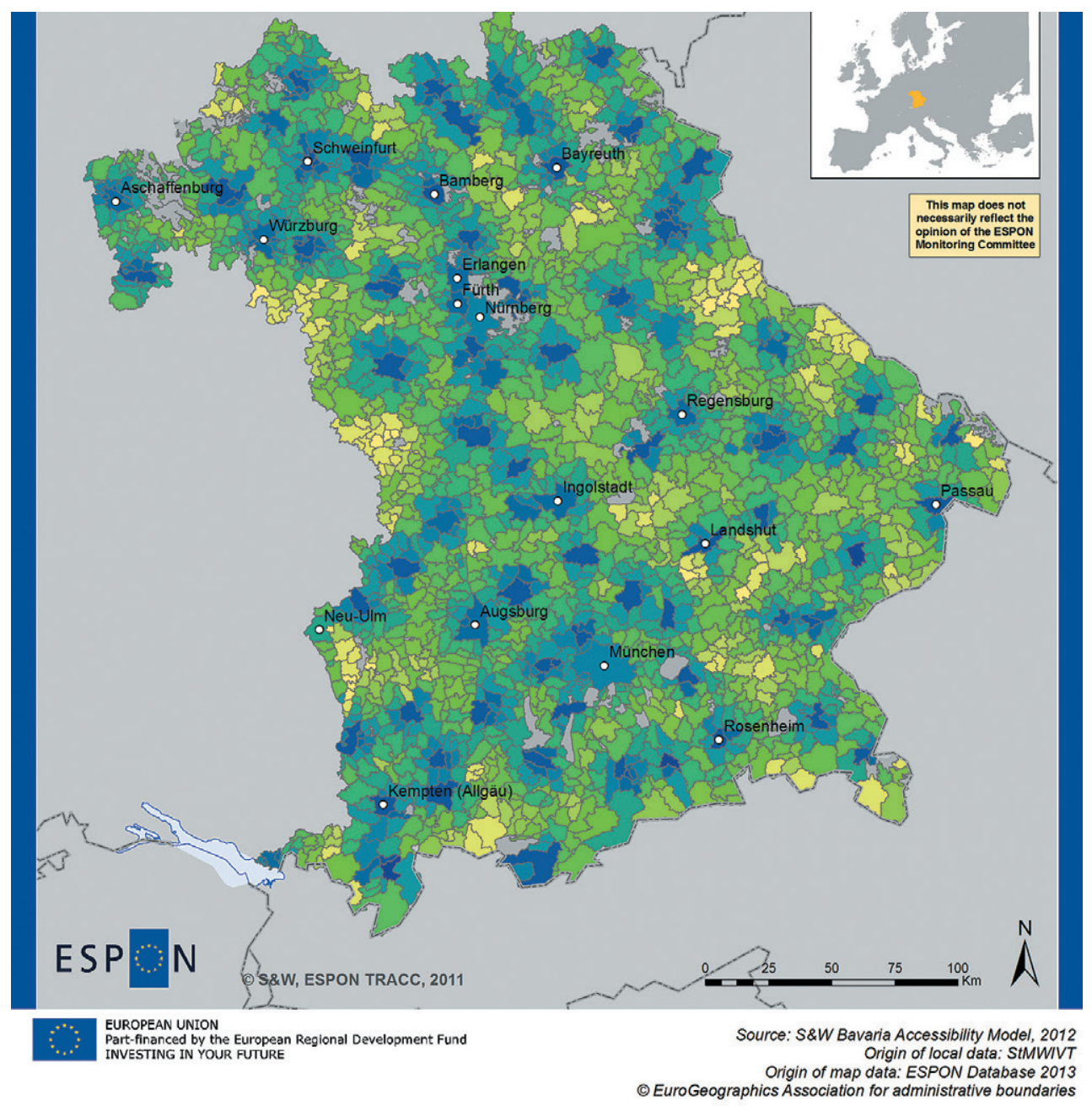

\section{Bavaria Case Study}

Travel time by public transport to next regional centre (minutes)
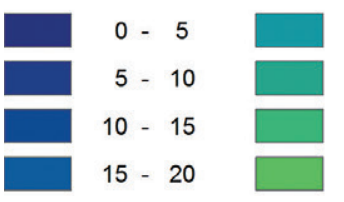

$30-35$
$35-40$
$40-45$
$45-50$

$60-65$

$65-70$

$70-75$

$75-80$

Figure 4. Travel time to nearest regional centre by public transport. 


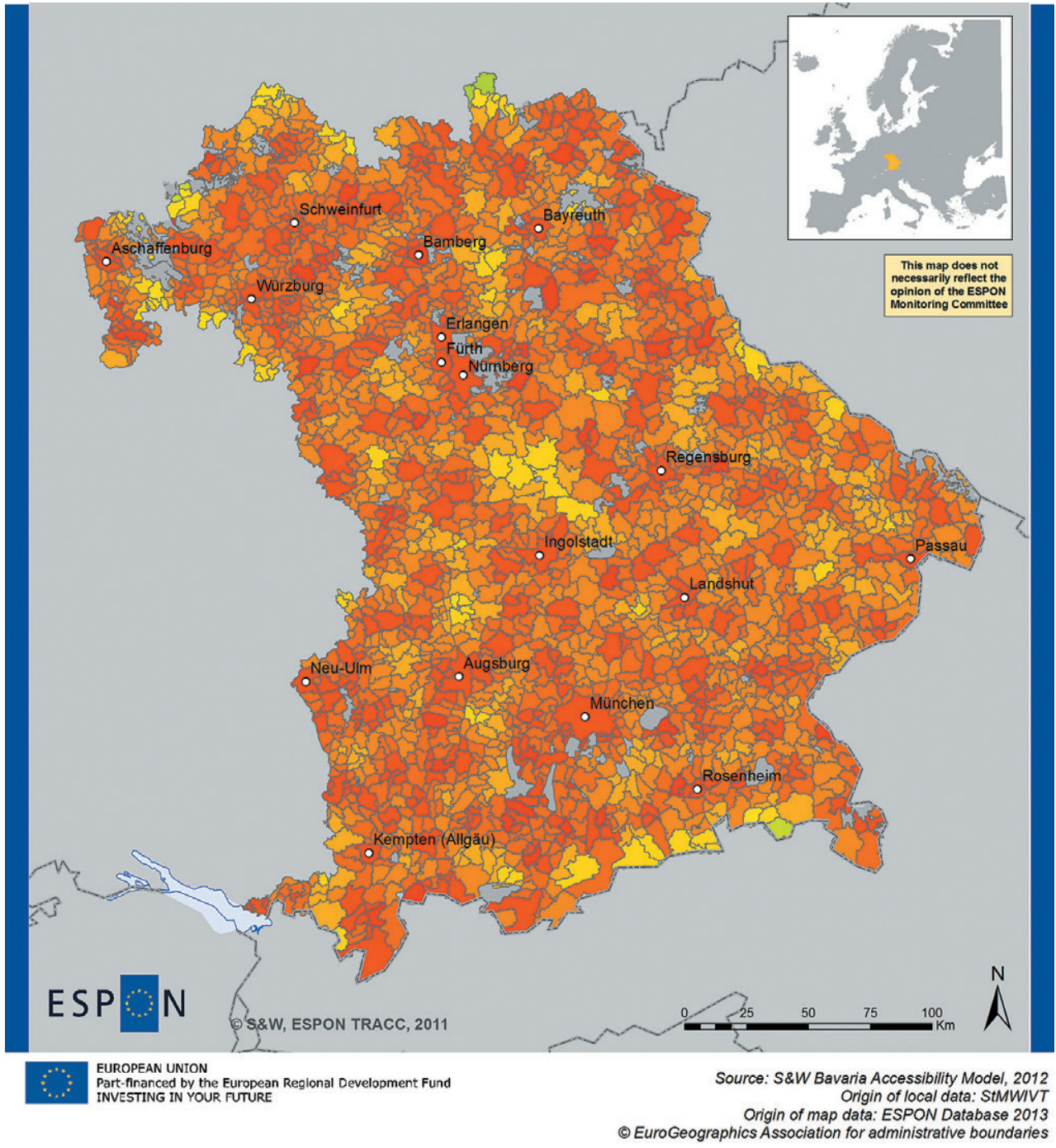

\section{Bavaria Case Study Car travel time to next hospital (minutes)}

\begin{tabular}{|c|c|c|}
\hline $0-5$ & $25-30$ & $50-55$ \\
\hline $5-10$ & $30-35$ & $55-60$ \\
\hline $10-15$ & $35-40$ & $60-65$ \\
\hline $15-20$ & $40-45$ & $65<$ \\
\hline $20-25$ & $45-50$ & Unincorporated area \\
\hline
\end{tabular}

Figure 5. Travel time to nearest hospital by car. 
Access to a regional centre by public transport

Regional centres offer a lot of services and amenities to the regional population. This includes all types of services of general interest, shopping facilities or cultural opportunities for most population groups including younger and elderly people who do not have access to a car or have it not very often. Therefore, an indicator of the access to regional centres by public transport reflects the possibility to take advantages of the opportunities offered by the regional centre for people who have no car.

For Bavaria, the administrative capitals of the counties have been used as regional centres. Figure 4 shows how long a public transport trip lasts from the municipalities to the nearest regional centre (expressed in minutes). The picture first shows the rather balanced distribution of regional centres across Bavaria. The emerging accessibility pattern is different from the two presented before. All over the Bavarian territory, there are areas with good access surrounded by areas with rather long travel times by public transport. Whereas the travel time from the municipalities directly surrounding the county capitals is below half an hour, the travel time from other municipalities increases significantly. All over the case study area, there are clusters of municipalities from which a public transport trip into the regional centre lasts more than one hour, from some municipalities even more than 90 minutes. The variations over different territorial typologies are relatively small. Whereas the average trip by public transport in Bavaria lasts 35 minutes, trips from urban areas last 30 minutes and trips from rural areas, with about 40 minutes on average, are only a little bit longer.

Car trips to regional centres take much less time and also the variations across the country are much less pronounced. The Bavarian average is about 20 minutes, from urban areas it is only a few minutes less, and from rural areas only a few minutes more. For most municipalities, travel time by car is only about half of the travel time by public transport.

\section{Access to health care facilities by car}

The access to services of general interest is an important factor for the quality of life. The availability of nearby kindergartens, schools, health care facilities (such as different kinds of doctors and hospitals) or public service agencies is an important location factor for residents and decisive for the daily mobility effort to be taken.

In Bavaria, the distribution of hospitals across the territory is relatively even. Travel times by car to municipalities are rather short with less than 15 minutes for many municipalities (Figure 5). However, there are also areas in Bavaria that are more apart from hospitals, with car travel times up to half an hour or even slightly more. The average travel time to a hospital by car is about 16 minutes. The variations across types of regions are insignificant. The average for urban areas is 12 minutes, the average for rural areas is 18 minutes. Travel to hospitals by public transport takes much longer. The Bavarian average is beyond half an hour.

\section{Conclusions}

The spatial differentiation of a case study region such as Bavaria from the point of view of accessibility depends on the type of destination opportunity under consideration very much. Accessibility of opportunities of basic needs seems rather balanced. However, accessibility of higher level services such as hospitals is distributed across the region less evenly. For such facilities, there are only some hundred locations in Bavaria and those are primarily located in cities that have a higher position 
in the city hierarchy. Between those central places, there are often wide areas with clearly lower accessibility. This is especially pronounced when accessibility by public transport is concerned.

However, spatial or temporal proximity, i.e. accessibility, is not the only criterion decisive of travel and destination decisions. Other features of the destinations, such as quantity and quality of the possible supply, individual evaluations and preferences of potential users, often prevent travelling to the nearest opportunity. However, the degree to which the population has a real choice in selecting opportunities to visit varies strongly between the services fulfilling the basic needs and advanced demand. For opportunities which fulfil the basic needs, the population mostly has different choices, even in rural parts of Bavaria. However, for opportunities serving higher demand there is a clear differentiation in the Bavarian territory. Whereas the municipalities in urban agglomerations, in particular the core cities, offer a high degree of freedom to choose a certain facility, this does not exist in rural areas. Here, sometimes population should be happy if there is any opportunity within reasonable reach at all.

Vast accessibility differences between car and public transport are noteworthy. This is in particular true if longer trips have to be made to reach the destinations of interest. On average, public transport travel times are twice as long as those for trips by car. This gap is even greater in rural areas.

It has to be taken into consideration that the accessibility analysis presented here only is a snapshot of the current situation. Accessibility is not static, but varies over time. Demographic change, economic pressure, political decisions and individual choices change the overall situation. In particular, the expected closure and concentration of several facilities of services of general interest such as schools or hospitals will have a negative effect on the accessibility situation of the population, in particular of the population of rural and remote municipalities. This leads to the conclusion that in the future integrated planning of locations of services of general interest, public transport services and new residential areas is decisive in ensuring an acceptable level of accessibility also for rural areas.

\section{References}

Biosca O., Spiekermann K., Stępniak M., 2013. Transport accessibility at regional scale. EUROPA XXI, vol. 24, pp. 5-17.

Schürmann C., Spiekermann K., Stępniak M., 2010. Erreichbarkeit ausgewählter zentralörtlicher Einrichtungen in Bayern. Studie für das Bayerische Staatsministerium für Wirtschaft, Infrastruktur, Verkehr und Technologie (StMWIVT). Abteilung Landesentwicklung. Dortmund und Oldenburg i.H.: S\&W and RRG.

Spiekermann K., 2013. TRACC Regional Case Study Book, Part C: Bavaria case study. [in:] K. Spiekermann, M. Wegener, V. Květoň, M. Marada, C. Schürmann, O. Biosca, A.U. Segui, H. Antikainen, O. Kotavaara, J. Rusanen, D. Bielańska, D. Fiorello, T. Komornicki, P. Rosik, Stępniak M., TRACC, Transport Accessibility at Regional/Local Scale and Patterns in Europe, Final Report Volume 3. Luxembourg: ESPON and Spiekermann \& Wegener, Urban and Regional Research (S\&W). 
http://rcin.org.pl 